\title{
Johanna Tuukkanen
}

\section{CURATORIAL PRACTICE EMBEDDED IN THE CITY}

\section{- A Case Study of Curating New Genre Public Art in Festival Context}

FM Johanna Tuukkasen taidekasvatuksen (kulttuuripolitiikan) väitöskirjan "Curatorial Practice Embedded in the City - A Case Study of Curating New Genre Public Art in Festival Context" tarkastustilaisuus pidettiin Jyväskylän yliopistossa 7. elokuuta 2020. Vastaväittäjänä toimi tutkija ja kuraattori, PhD Taru Elfving (Goldsmiths College, Lontoo) ja kustoksena professori Pauline von Bonsdorff (Jyväskylän yliopisto).

Uskon, että jokainen läsnäolija tässä salissa on joskus käynyt taidemuseossa, galleriassa, teatterissa, festivaalilla tai jossakin taidetapahtumassa ja saanut omakohtaisia kokemuksia näyttelyistä, installaatioista, esityksistä, konserteista tai muista elävistä taidetapahtumista. Tai ehkäpä olet kiinnittänyt huomiosi julkisiin taideteoksiin niissä kaupungeissa, joissa olet vieraillut, kuten vaikkapa tuohon bysantinsiniseen teräksiseen Pero Luostarisen Yliopistoporttiin (1987) täällä Seminaarimäellä Jyväskylässä. Tai kenties olet käynyt jollakin suurista kaupunkifestivaaleista, jotka järjestävät taidetapahtumia julkisissa tiloissa ja houkuttelevat isoja yleisöjä, kuten esimerkiksi Lux Helsinki valotaidetapahtuma, jossa viime tammikuussa vieraili noin 600000 kävijää.

Olitpa sitten kokenut kuvataidenäyttelyitä, konsertteja, tanssi-, teatteri tai live art -esityksiä, esitystaidetta, julkista taidetta tai paikkasidonnaista taidetta arkipäiväisissä tiloissa ja paikoissa, taiteenalasta riippumatta joku on suunnitellut nuo tapahtumat, valinnut taiteilijat ja taideteokset, ja organisoinut sen kaiken. Tuo "joku" on yleensä kuraattori.

Kuraattori-sanan alkuperä on latinankielisessä sanassa curare, joka tarkoittaa huolehtimista, pitää huolta jostakin. Perinteisessä merkityksessään 1800-luvun loppupuolelta alkaen kuraattoria voidaankin kuvailla esineiden ja kokoelmien huolehtijana. Tämä toiminta jatkuu yhä museoissa, joilla on kokoelmia ja arkistoja, mutta kuraattorin rooli on laajentunut huomattavasti 1960-luvulta lähtien kohti näyttelyiden kokoajaa ja itsenäisesti toimivaa taidemaailman ammattilaista, joka ei ainoastaan luo näyttelyitä ja työskentele kokoelmien parissa museoissa ja gallerioissa, vaan joka suunnittelee tapahtumia, johtaa itsenäisesti toimivia tapahtumapaikkoja ja taideorganisaatioita, tekee julkaisuja, työskentelee vierailevana kuraattorina kansainvälisissä taidebiennaaleissa tai esimerkiksi taiteilijaa, joka toimii myös kuraattorina. Ammattina ja akateemisena tutkimusalana kuraattorius on 
verrattain nuori ilmiö, sillä ensimmäiset yliopistotasoiset kuraattorikoulutukset alkoivat vuonna 1986 Ranskassa ja Yhdysvalloissa. Tämän vuoksi ei olekaan olemassa yhtä ainoaa koulutusreittiä kuraattoriksi, ja monien kuraattoreiden koulutustausta on taidehistoriassa, estetiikassa, taidehallinnossa, dramaturgiassa, teatteritieteessä tai filosofiassa, mikä tarkoittaa sitä, että myös kuratoriaalinen diskurssi eli keskustelu kuraattoreiden toiminnasta on verrattain uutta.

Kuten olet saattanut huomata mediassa, kuratoiminen on myös levinnyt taidemaailmasta kaikenlaisille sektoreille, missä hallinnoidaan ja välitetään sisältöjä. Tänä päivänä erilaisia asioita soittolistoista ruokaan ja kahviin voidaan kuratoida juuri sinulle, ja itse asiassa monet kuraattorit ovatkin kriittisiä kuratointi-sanan varastamisesta sellaisiin konteksteihin kuin valokuvien järjestäminen, muoti ja jopa Instagram-syöte. Monet taidekuraattorit kommentoivat tätä kuratoinnin väärinkäyttöä sosiaalisessa mediassa aihetunnisteella \#curate-abuse.

Vaikka tässä suhteessa onkin trendikästä tutkia kuratoriaalisia käytänteitä eli kuraattoreiden työtä ja toimintaa, tutkimukseni sytykkeenä on toiminut se, että minua vaivasi, miten kuratoriaalisia käytäntöjä kontekstualisoitiin ja kuvailtiin alan viimeaikaisessa kirjallisuudessa. Kuratoriaalisista käytänteistä, millä tarkoitan kuraattoreiden tapoja työskennellä ja sitä mitä he tekevät, keskustellaan enimmäkseen kuvataiteen kontekstissa eli museoiden, gallerioiden ja biennaalien yhteydessä, ja oletuksena on, että työskentelyn muotona on näyttely. Mutta jos ajattelemme sitä, miten taiteelliset käytänteet ovat viime vuosikymmenien aikana muuttuneet, huomaamme, että monet taiteen tekemisen tämänhetkiset muodot ovat radikaalisti muuttuneet kohti julkisissa tiloissa tapahtuvia paikkasidonnaisia ja sosiaalisesti sitoutuneita käytäntöjä, jota usein kuvaillaan 1990 ja 2000-lukujen taiteen sosiaaliseksi käänteeksi. Tämä tarkoittaa sitä, että monet taiteilijat työskentelevät kaupunkitiloissa paikkasidonnaisesti ja tekevät yhteistyötä erilaisten yhteisöjen kanssa sitouttaen moninaisia ihmisiä taiteen tekemisen prosesseihin. Tutkimuksessani sijoitan tällaiset taideteokset uuden julkisen taiteen käsitteen alle, mikä on alun perin amerikkalaisen taiteilijan Suzanne Lacyn luoma käsite 1990-luvulla. Tätä kehityskulkua seuraten on yllättävää, kuinka vähän on tehty tutkimusta taiteellisten ohjelmistojen kuratoinnista museoiden, gallerioiden ja teattereiden eli niin sanottujen perinteisten taiteen tilojen ja instituutioiden ulkopuolella.

Väitöstutkimukseni on monitieteistä ja monimenetelmällistä liittyen taiteentutkimuksen, kulttuuripolitiikan ja kulttuurintutkimuksen alueille. Olen tutkimuksessani keskittynyt uuden julkisen taiteen parissa tapahtuviin kuratoriaalisiin käytänteisiin festivaalien yhteydessä. Olin kiinnostunut tutkimaan kuraattorin roolia ja käytäntöjä paikkasidonnaisen ja sosiaalisesti sitoutuneiden taideteosten ohjelmistosuunnittelun prosesseissa. Valitsin tutkimukseeni neljä kansainvälistä festivaalia tapauksiksi, sillä olin kiinnostunut käytänteistä ja säännöllisesti järjestettävät ja toistuvat festivaalit tarjosivat hedelmällisen kontekstin näiden käytäntöjen tutkimiselle. Tutkimukseni tapausfestivaalit ovat Metropolis Kööpenhaminassa, Tanskassa, Steirischer Herbst Grazissa, Itävallassa, IHME-festivaali Helsingissä, Suomessa, ja PLACCC Budapestissa, Unkarissa. Menetelmällisiltä lähtökohdiltaan tutkimukseni on laadullinen monitapaustutkimus. Mutta sen sijaan että olisin lähtenyt vertailemaan tapauksia, olen tutkimuksessani kuvannut uuden julkisen taiteen kuratoriaalisia käytänteitä festivaalikontekstissa laajempana ilmiönä.

Tutkimukseni tuottaa uutta tietoa taiteen ajankohtaisista kuratoriaalisista käytänteistä ja laajentaa kuraattoreiden työstä käytävää keskustelua taideinstituutioista kohti kaupunkitilassa tapahtuvaa toimintaa. Toiveeni on, että sitä voidaan hyödyntää niin kuraattoritutkimuksen, taiteen tutkimuksen kuin festivaali- ja kaupunkitutkimuksenkin alueilla sekä laajasti kulttuurialan koulutuksessa. Näkemykseni mukaan kuraattoreiden tiedon ja osaamisen soveltamisessa myös esimerkiksi kaupunkisuunnittelussa on valtavasti hyödyntämätöntä potentiaalia. Suunnitellessaan festivaalien ohjelmistoja he luovat monenlaisia osallistumisen mahdollisuuksia 
kaupunkilaisille ja rakentavat kohtaamisille perustuvaa kaupunkikulttuuria, jotka laajentavat kaupunkitilan käyttömahdollisuuksia ja erilaisten oleskelumuotojen potentiaalia. Näin uuden julkisen taiteen parissa toimivien kuraattoreiden ammattitaitoa olisi mahdollista hyödyntää kaupunkisuunnittelussa ja erilaisissa kehittämishankkeissa muutoinkin kuin vain yksittäisten taidehankintojen ja hankkeiden tai taiteen prosenttiperiaatteen toteuttamisessa.

Kokonaisuudessaan tutkimukseni auttaa ymmärtämään paremmin sitä, mitä kuraattorin työ on tänä päivänä globaalin taidemaailman ja paikallisen kontekstin välissä. Kuraattoritutkimukselle kontribuutioni on uuden julkisen taiteen kuratoinnin tiedon lisäämisen ohella keskustelu kuratoriaalisista käytännöistä taiteen teorian, tilan teorian ja poliittisen teorian risteyskohdassa.

Vaikka kuratoriaalisissa käytänteissä on yhteneväisyyksiä kontekstista riippumatta, kaupunkitilassa tapahtuva uusi julkinen taide asettaa sille ihan omanlaisiaan haasteita ja kysymyksiä. Ei ole sama asia toimia kuraattorina museossa kuin kaupunkitilassa. Kaupunkitilan alati muuttuva käyttö sekä vaihtelevat olosuhteet säästä katutöihin ja kaduilla liikkuviin ihmisiin on konteksti, jota ei voi kontrolloida, mikä aiheuttaa lukuisia haasteita, ei vain taiteilijalle, vaan myös kuraattorille. Kuraattorin on huomioitava julkinen tila, sen käyttö, jatkuva muuttuminen, kaupallistuminen ja yksityistyminen sekä erilaiset lupaprosessit, jotka saattavat vaikuttaa merkittävästi heidän taiteellisiin kiinnostuksiinsa. Mitä on mahdollista toteuttaa ja missä? Ja yhteistyössä kenen kanssa? Eri kaupungit erilaisine rakenteineen, instituutioineen, yrityksineen, yhteisöineen ja ihmisineen mahdollistavat, mutta samaan aikaan myös rajoittavat erilaisia asioita. Kaupunkitilassa työskentely nostaa esiin myös kysymyksiä yleisöstä. Kuinka määritellä ja tavoittaa yleisö? Ja entäpä taideteoksiin osallistuminen ja sitoutuminen? Tutkimukseni tarjoaakin mahdollisuuden tarkastella kuraattoreiden toimintaa toimintaympäristössä, joka on kaupunki, ei vain joku taidemaailman instituutio - tai kuten Luigi Fassi, yksi haastatelluista kuraattoreista sanoo:
You have the city as a curator, you know the artist. You have to kind of bring the two things together. (Luigi Fassi, Steirischer Herbst)

Tutkimukseni keskeiset tulokset voi tiivistää kolmeen kohtaan. Ensinnäkin tutkimus osoittaa, että uuteen julkiseen taiteeseen liittyvät kuratoriaaliset käytännöt festivaalikontekstissa ovat kaupunkiin sulautuneita performatiivisia ja ei-representaationalisia käytäntöjä. Tämä tarkoittaa sitä, että niiden juuret ovat arkipäivän elämässä ja ne ovat paikallisesti kiinnittyneitä kulloinkin kyseessä olevaan kaupunkiin. Nämä käytännöt ovat läpikotaisin dialogisia ja perustuvat jatkuvaan kuraattorin, taiteilijoiden ja kaupungin väliseen dialogiin.

Tällaiset kaupunkiin sulautuneet käytännöt vaativat kuraattoreilta taidemaailman asiantuntemuksen lisäksi paikallistuntemusta ja läsnäoloa kaupunkitilassa ja ne ovat luonteeltaan pitkäkestoista. Niitä voi kuvailla myös lainausmerkeissä "glokaaleiksi", sillä kuraattoreiden toiminnassa yhdistyvät paikallisesti ajankohtaiset kysymykset ja teemat sekä globaalin taidemaailman ilmiöt.

Toiseksi löysin tapausfestivaaleilta tutkimuksessani kolme poliittista agendaa, jotka ovat taidemaailman, sosio-poliittinen ja urbaani agenda. Vaikka ne ovat osittain päällekkäisiä, agendat osoittavat kuinka festivaalikontekstissa kuratoriaaliset käytännöt ulottuvat näille kolmelle alueelle, sillä kuraattoreiden toiminta perustuu festivaalien poliittisille agendoille. Kuraattorit eivät siis toimi ainoastaan taidemaailmassa, vaan heillä on mahdollisuuksia ja valtaa vaikuttaa kaupunkitilassa tapahtuvaan toimintaan, niihin teemoihin ja aiheisiin, joita taideteokset käsittelevät sekä niihin mahdollisuuksiin, joita sinulla ja minulla, ja kulloinkin kyseessä olevan kaupungin asukkailla ja yhteisöillä on kohdata taidetta, olla tekemisissä taiteen kanssa ja tavata toisiamme kaupunkitilassa.

Kolmas keskeinen löydös on, että kuraattoreiden tavoitteet luoda kohtaamisia sisältää poliittisen eli asioiden muuttumisen mahdollisuuden. Tapausfestivaalit kiinnittyvät paikalliseen urbaaniin kontekstiin, tuovat taiteilijoita ja kansalaisia osaksi luovaa ja aktiivista kaupunkitilan 
tuottamisen prosessia ja festivaalit siten luovat mahdollisuuksia kokoontumisille, kohtaamisille ja vuorovaikutukselle. Julkisessa tilassa tapahtuva taiteellinen ja luova toiminta sisältää mahdollisuuden arkipäivän muuntautumiselle. Kun ymmärrämme, että urbaanin lähtökohta on kohtaaminen, johon liittyy leikillisyyden ja ennakoimattomuuden elementtejä, ja muistamme, että urbaania täytyy jatkuvasti tuottaa ja uudelleen tuottaa, tämän mahdollisuuden vaalimi- nen ja korostaminen on tärkeää. Filosofi Henri Lefebvren käsitys urbaanista kurottaa olemassa olevasta todellisuudesta kohti mahdollisuutta ja lupausta. Tutkimukseni osoittaakin, että arkipäivään uppoutuneet kohtaamiset liittävät kuratoriaaliset käytännöt ajatuksiin potentiaalista, mahdollisuudesta ja kokeilusta - hetkiin, jolloin voimme kuvitella meille kaikille viihtyisämmän ja kestävämmän kaupungin elää ja asua.

\section{Lähteet}

Kester, G. (2011). The One and the Many: Contemporary Collaborative Art in a Global Context. Duke University Press.

Lacy, S. (ed.). (1995). Mapping the Terrain: New Genre Public Art. Seattle, Washington: Bay Press.

Lefevbre, H. (1991). The Production of Space. Translated by Donald Nicholson-Smith. Oxford: Blackwell Publishers.

Lefebvre, H. (1996). Writings on Cities. Oxford: Blackwell Publishers.

O'Neill, P. (2012). The Culture of Curating and the Curating of Culture(s). Cambridge, Massachusetts and London, England: The MIT Press.

Rancière, J. \& Corcoran, S. (2015). Dissensus. On Politics and Aesthetics. Translated with an Introduction by Steven Corcoran. London, New York: Bloomsbury. 